\title{
Bacteroides meningitis complicating chronic mastoiditis
}

\author{
D. SIEGLER \\ M.D., M.R.C.P. \\ M. C. FAIERS \\ M.B., M.R.C.Path. \\ A. T. WILLIS \\ M.D., F.R.A.C.P.
}

Department of Medicine and Public Health Laboratory, Luton and Dunstable Hospital, Luton, Beds.

\begin{abstract}
Summary
A 70-year-old man with a history of chronic middle and external ear suppuration presenting with acute meningitis due to Bacteroides uniformis is described. Anaerobic organisms including Bacteroides species were cultured from the affected external auditory meatus. Administration of metronidazole led to complete clinical recovery and a cholesteatoma was subsequently surgically evacuated. Chronic suppuration in the middle ear and paranasal sinuses is the commonest primary cause of cerebral abscess and in this setting meningitis is associated with a particularly high mortality. The major role of anaerobic sepsis in otolaryngological practice is well established. Metronidazole is the chemotherapeutic agent of choice.
\end{abstract}

\section{Introduction}

Chronic middle ear infection is the commonest primary source of intracranial suppuration. This report describes a case of Bacteroides meningitis secondary to chronic mastoiditis, and the excellent response to metronidazole.

\section{Case report}

A 70-year-old retired technical author developed severe occipital headache of sudden onset, subsequently radiating to the neck, $7 \mathrm{hr}$ before admission to hospital. His past medical history included left mastoidectomy $\mathbf{4 0}$ years earlier, followed by hearing loss in the left ear and a chronic purulent discharge from the external auditory meatus. On examination he was apyrexial but distressed by headache. Signs of meningism were present, but no other physical abnormality. A full blood count and biochemical screen were normal. Lumbar puncture yielded a slightly turbid cerebrospinal fluid (CSF) under normal pressure, containing white blood cells $0.062 \times 10^{9} / 1$, of which $85 \%$ were lymphocytes. No organisms were seen on Gram or Ziehl-Nielsen staining. The CSF glucose was $2.6 \mathrm{mmol} / 1$ (simultaneous blood glucose 5.6) and the protein $1.3 \mathrm{~g} / 1$. CSF 8 bacterial cultures were negative. Symptomatic treat- $\omega$ ment was administered, but in view of his subsequent $\triangle$ deterioration with confusion and pyrexia, and despite $ᄋ$ the absence of meningism, a second lumbar puncture was performed on the 6th hospital day. Turbid CSF $\infty$ was obtained containing $1.15 \times 10^{9} / 1$ white blood $\mathbb{O}$ cells, of which $80 \%$ were polymorphonuclear. The $\frac{\mathbb{\mathbb { T }}}{3}$ CSF sugar was $0.8 \mathrm{mmol} / 1$ and the protein $2.8 \mathrm{~g} / 1$. 응 Gram stain revealed numerous slender Gram-neg $\mathbb{Q}$ tive bacilli, and although direct gas-liquid chromate $\overrightarrow{0}$ graphy was negative, culture yielded a heavy grow of Bacteroides uniformis. A swab of the discharge from the left ear grew a mixture of Proteus species and mixed anaerobic organisms including Bacteroides melaninogenicus. Metronidazole $400 \mathrm{mg} 8$-hourly was given orally with rapid and complete clinical $\frac{\otimes}{\varnothing}$ recovery. An isotope brain scan was normal. Tomo- $\cong$ graphy of the left internal auditory meatus showed $\overrightarrow{\vec{O}}$ thinning of the tegmen tympani in association with 3 cavitation (Fig. 1). Three weeks following admission revision of the left mastoidectomy was carried out and a cholesteatoma evacuated. Two fistulae were noted in the lateral semi-circular canal. The postoperative course was uneventful.

\section{Discussion}

This report describes a case of Bacteroides men- 을 ingitis secondary to chronic otitis media and choles- $\rightarrow$ teatoma. Anaerobic meningitis in the absence of $\mathrm{O}$. cerebral abscess is uncommon and is usually due to $N$ chronic otitis media or mastoid surgery (Peterson, Voorhees and Elder, 1979). Jefferson and Keogh $N$ (1977) emphasized that middle ear infection is the $\underset{\omega}{ }$ commonest primary source of cerebral abscess and 0 that meningitis in association with cerebral abscess 0 carried a particularly high mortality. The importance $\frac{\mathbb{D}}{\mathbb{2}}$ of anaerobic organisms as a cause of cerebral abscess associated with spread from chronic suppuration in 0 the middle ear and paranasal sinuses is now well 


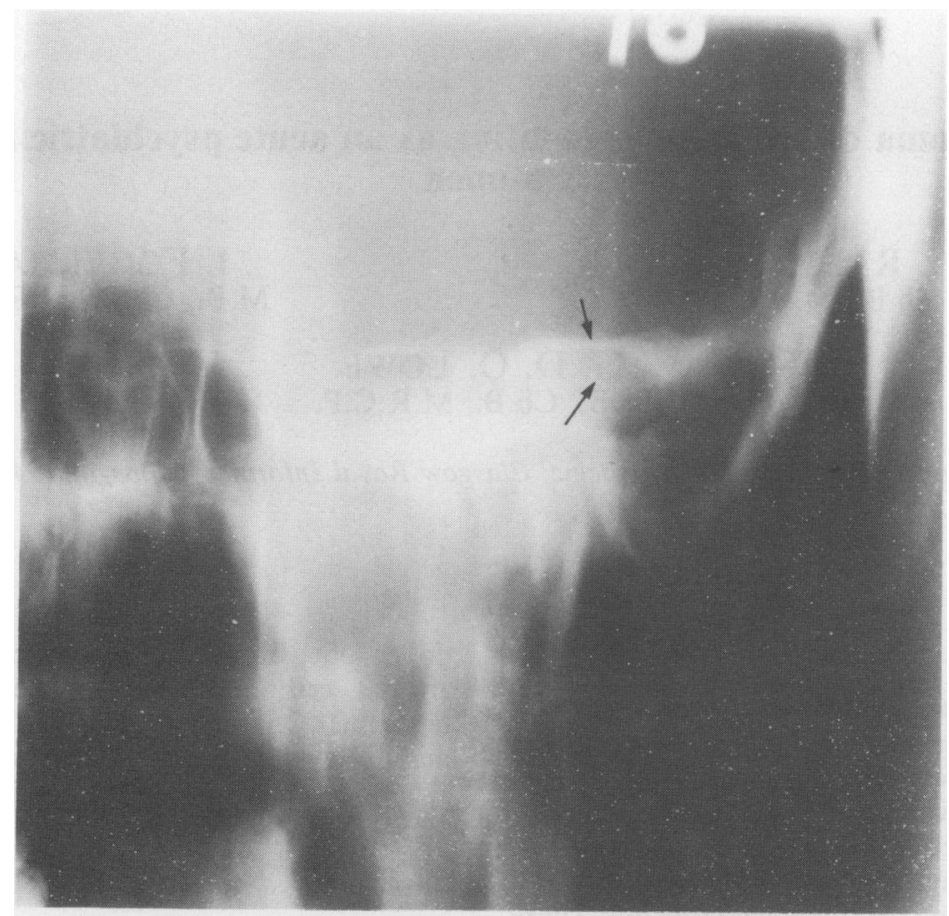

FIG. 1. Tomography of left middle ear (Stenver's view) showing marked thinning of the tegmen tympani (upper arrow) in association with cavitation (lower arrow).

established, as is the role of metronidazole as the best available therapeutic agent (Ingham and Selkon 1976; Ingham, Selkon and Roxby, 1977).

Bacteroides meningitis may follow rupture of a cerebral abscess or complicate suppuration in the middle ear or paranasal sinuses. Other predisposing factors include neurosurgical procedures and head and abdominal trauma (Heerema et al., 1979). Islam and Shneerson (1980) described an apparently unique case diagnosed at autopsy with no alternative primary site of infection. Neonatal Bacteroides meningitis may lead to hydrocephalus unless promptly diagnosed and treated (Law and Marks, 1980).

The true frequency of anaerobic meningitis is probably underestimated, because anaerobic cultures of CSF are not routinely performed (Chattopadhyay, 1977; Heerema et al., 1979). This is particularly important in cases of pyogenic meningitis with negative aerobic cultures despite no previous chemotherapy. A previous report from this hospital (Beeden and Willis, 1980) has stressed the importance of anaerobic infection in ear, nose and throat practice, the occurrence of intracranial sepsis secondary to middle ear infection and the rapid response to metronidazole.

\section{References}

BEEDEN, A.G. \& WILLIS, A.T. (1980) A case of anaerobic middle ear infection with complications. Journal of Laryngology and Otology, 94, 659.

ChATtOPADhYAY, B. (1977) Bacteroides fragilis meningitis. Lancet, i, 1371.

Heerema, M.S., Ein, M.E., Musher, D.M., Bradshaw, M.W. \& WILliams, T.W. (1979) Anaerobic bacterial meningitis. American Journal of Medicine, 67, 219.

INGHAM, H.R. \& SELKON, J.B. (1976) Cerebral abscess. Journal of Antimicrobial Chemotherapy, 2, 224.

INGHAM, H.R., SELKON, J.B. \& ROXBY, S.M. (1977) Bacteriological study of otogenic cerebral abscesses: chemotherapeutic role of metronidazole. British Medical Journal, 2, 991.

IsLaM, A.K.M.S. \& SHNEeRsON, J.M. (1980) Primary meningitis caused by Bacteroides fragilis and Fusobacterium necrophorum. Postgraduate Medical Journal, 56, 351.

JEFFERSON, A.A. \& KEOGH, A.J. (1977) Intracranial abscesses: a review of treated patients over 20 years. Quarterly Journal of Medicine, N.S. 46, 389.

LAW, B.J. \& MARKS, M.I. (1980) Excellent outcome of Bacteroides meningitis in a newborn treated with metronidazole. Pediatrics, 66, 463.

PETERSON, D.I., VOORHEes, E.G. \& ElDER, H.A. (1979) Bacteroides meningitis successfully treated with metronidazole. Annals of Neurology, 6, 364. 